\title{
ANATOMICAL VARIATIONS OF THE BRACHIAL PLEXUS TERMINAL BRANCHES IN ETHIOPIAN CADAVERS
}

\author{
Edengenet Guday Demis ${ }^{*}$, Asegedeche Bekele*
}

Corresponding Author: Edengenet Guday Demis, 196, University of Gondar, Gondar, Ethiopia. Email: edengeneta@gmail.com

\begin{abstract}
Anatomical variations are clinically significant, but many are inadequately described or quantified. Variations in anatomy of the brachial plexus are important to surgeons and anesthesiologists performing surgical procedures in the neck, axilla and upper limb regions. It is also important for radiologists who interpret plain and computerized imaging and anatomists to teach anatomy. This study aimed to describe the anatomical variations of the terminal branches of brachial plexus on 20 Ethiopian cadavers. The cadavers were examined bilaterally for the terminal branches of brachial plexus. From the 40 sides studied for the terminal branches of the brachial plexus; 28 sides were found without variation, 10 sides were found with median nerve variation, 2 sides were found with musculocutaneous nerve variation and 2 sides were found with axillary nerve variation. We conclude that variation in the median nerve was more common than variations in other terminal branches.
\end{abstract}

\section{Key words:}

\section{INTRODUCTION}

The brachial plexus is usually formed by the fusion of the anterior primary rami of the $\mathrm{C} 5-8$ and $\mathrm{T} 1$ spinal nerves. It supplies the muscles of the back and the upper limb. The $\mathrm{C} 5$ and $\mathrm{C} 6$ fuse to form the upper trunk, the $\mathrm{C} 7$ continues as the middle trunk and the $\mathrm{C} 8$ and $\mathrm{T} 1$ join to form the lower trunk. Each trunk divides into anterior and posterior divisions. The anterior divisions of the upper and middle trunks form the lateral cord; the anterior division of the lower trunk continues as the medial cord and the posterior divisions of all three forms the posterior cord. The cords then give rise to various branches that form the peripheral nerves of the upper limb. Anterior divisions of the trunks supply anterior (flexor) compartments of the upper limb, and posterior divisions of the trunks supply posterior (extensor) compartments. Since the brachial plexus is a complex structure, variations in formation of roots, trunks, divisions and cords may occur (Moore and Dalley, 1992, Standring et al., 2005).

Most nerves in the upper limb arise from the brachial plexus; it begins in the neck and extends into the axilla. Almost all branches of the brachial plexus supplying the upper limb arise in the axilla (after the plexus has crossed the 1st rib) (Moore and Dalley, 1992).

The brachial plexus is divided into supraclavicular and infraclavicular parts by the clavicle. Four branches of the supraclavicular part of the plexus arise from the roots and trunks of the brachial plexus namely dorsal scapular nerve, long thoracic nerve, nerve to subclavius and suprascapular nerve and are approachable through the neck. In addition, officially unnamed muscular branches arise from all five roots of the plexus, which supply the scaleni and longus colli muscles. 
Branches of the infraclavicular part of the plexus arise from the cords of the brachial plexus and are approachable through the axilla. Counting side and terminal branches, three branches arise from the lateral cord namely lateral pectoral nerve, musculocutaneous nerve ( terminal branch) and lateral root of median nerve (terminal branch), five branches arise from the medial cord namely medial root of median nerve (terminal branch), medial pectoral nerve, medial cutaneous nerve of the arm, median cutaneous nerve of the forearm and ulnar nerve (terminal branch) and five branches arise from the posterior cord namely upper subscapular nerve, lower subscapular nerve, thoracodorsal nerve, axillary nerve(terminal branch) and radial nerve (terminal branch) (Moore and Dalley, 1992, Drake et al., 2014).

The topography of the brachial plexus and its anatomical variation play an essential role in diagnoses, therapy and surgical procedures (Loukas et al., 2008, Johnson et al., 2010).This variation may lead to deviation from the expected dermatome distribution as well as differences in the motor innervation of muscles of the upper limb. Such variations may predispose patients to certain pathology such as thoracic outlet syndrome and may alter surgical approaches to the brachial plexus (Pellerin et al., 2010). Variation in brachial plexus formation and branching pattern has clinical implications as it may result in failure of regional brachial or axillary block (Moore and Dalley, 1992).
Anatomical variations have clinical significance to surgeons and radiologists who interpret plain and computerized imaging and to those anesthesiologists who place needles to administer anesthetic blocks. The awareness of these variations is of interest to the surgeons, neurologists and radiologist (Harry et al., 1997). So, a thorough understanding of the neuroanatomy of the brachial plexus, with an appreciation of the possible anatomic variations that may occur is necessary for effective clinical practice. Anatomical Variations may occur in the origin and/or combination of branches and in the relationship to the axillary artery and scalene muscles (Moore and Dalley, 1992, Loukas et al., 2008, Johnson et al., 2010)

Anatomical variation of the brachial plexus is clinically important as this knowledge may help the anesthesiologists and the surgeons to avoid any inadvertent damage to nerves and blood vessels during blocks and surgical interventions. Knowledge of anatomical variations in brachial plexus branching pattern is also important to radiologists who interpret plain and computerized imaging and anatomists who teach anatomy for medical and paramedical students. The aim of this research was an assessment of anatomical variation of the brachial plexus terminal branches on 20 Ethiopian cadavers in selected medical schools in Ethiopia.

\section{MATERIALS AND METHODS}

Observational based descriptive study design was conducted to assess anatomical variation of the brachial plexus terminal branches on 20 Ethiopian cadavers. Purposive sampling technique was used for selecting 20 cadavers from the available limited number of cadavers obtained from Gondar, Bahir Dar, Hawasa, Addis Ababa universities, Hayat Medical College and St. Paul Hospital Millennium Medical College Departments of Human Anatomy. They were embalmed according to conventional methods by using formalin, alcohol, glycerin and phenol for routine dissection sessions and the materials necessary to collect data were blade, forceps, gloves, camera and a check list.

Data collection procedure was by using the dissection manual Cunningham (Cunningham, 1903). The brachial plexus was exposed in the left and right of 20 cadavers and the anatomy of brachial plexus (terminal branches) and its relationship with muscles and blood vessels around were inspected in the axilla and upper 
limb. All of the dissections were photographed and recorded.

To expose terminal branches of the brachial plexus skin incisions were made along the middle of the sternum vertically, extending the incision along the clavicle horizontally to its acromial end and another incision from the sternum to the axilla. The flaps of skin and superficial fascia were reflected laterally by blunt dissection, and deep fascia in the deltopectoral groove divided. The fascia from the anterior part of pectoralis major and deltoid were removed and the clavicular head of pectoralis major cut across below the clavicle and reflected towards its insertion. The remainder of the pectoralis major was cut about $5 \mathrm{~cm}$ from the sternum and its parts reflected medially and laterally. The clavipectoral fascia was removed from pectoralis minor to expose the vessels and nerves in the axilla. Loose connective tissue, fat and lymph nodes were removed from the axilla to expose its contents. The coracobrachialis and short head of biceps muscles was exposed and the median nerve and axillary artery medial to these muscles identified, together with musculocutaneous nerve entering the deep surface of coracobrachialis. Axillary artery and vein and the large nerves surrounding them were exposed and the ulnar nerve identified, lying behind and between the artery and vein, while the radial nerve lies behind the artery. The radial nerve was traced upwards and at the lower border of subscapularis and the axillary nerve identified passing backwards with the posterior humeral circumflex artery. The medial, lateral and posterior cords of the brachial plexus which are found around the axillary artery were exposed.

To ensure quality of data, after dissection, the dissected specimen was photographed and clarity was checked by the advisor. The quality checking was done at the end of each dissection and cross-checking was done before analysis.

Thematic approach was applied to compile and analyze findings on anatomical variations of brachial plexus formation and terminal branches.

Ethical clearance was obtained from school of medicine ethical review committee of University of Gondar. Study subjects are prepared for teaching purposes in the departments of human anatomy. An official letter was submitted to Bahir Dar University, Hawasa University, Addis Ababa University, Hayat Medical College and St. Paul Hospital Millennium Medical College. The purpose and the importance of the study were explained. Confidentiality was maintained at all levels of the study.

\section{RESULTS}

A total of twenty (16 male and 4 female) cadavers were observed to assess the anatomical variation of brachial plexus terminal branches in Gondar University, Bahir Dar University, Addis Ababa University, Hawasa University, Hayat Medical College and St. Paul Hospital Millennium Medical College, Ethiopia.

\section{Terminal branches of brachial plexus}

Brachial plexus gives five terminal branches. They are axillary, radial, musculocutaneous, median and ulnar nerves. From the 20 cadavers or 40 sides observed, 28 sides were found without variation, 10 sides were found with median nerve variation, 2 sides were found with musculocutaneous nerve variation and 2 sides were found with axillary nerve variation.

Out of the 28 sides which were found without variation, 11 were bilateral and 6 were unilateral. From the unilateral, 2 of them were found on the left side and the remaining was on the right side. Out of the 10 sides which were found with median nerve variation, 3 were bilateral and 4 were unilateral. From the unilateral, 3 of them were found on the left side and 1 on the right side. The musculocutaneous nerve variations were found unilaterally, one found on the right side and the other on the left side. Axillary nerve variations were found unilaterally in which 2 of them were found on the left side. 
Table 1: Terminal branches of the brachial plexus in 20 Ethiopian cadavers, 2012.

\begin{tabular}{|c|c|c|c|}
\hline \multirow{2}{*}{$\begin{array}{l}\text { Cadaver } \\
\text { label }\end{array}$} & \multirow[t]{2}{*}{ Sex } & \multicolumn{2}{|l|}{ Terminal branches } \\
\hline & & Rt side & Lt side \\
\hline 1 & M & Typical & Typical \\
\hline 2 & M & $\begin{array}{l}\text { Median nerve has one additional contribution from } \\
\text { the lateral cord }\end{array}$ & $\begin{array}{l}\text { Median nerve has one additional contribution } \\
\text { from the lateral cord }(\mathrm{mn})\end{array}$ \\
\hline 3 & M & $\begin{array}{l}\text { Musculocutaneous nerve arises from the median } \\
\text { nerve }\end{array}$ & Typical \\
\hline 4 & $\mathrm{~F}$ & $\begin{array}{l}\text { Median nerve has one additional contribution from } \\
\text { the lateral cord }\end{array}$ & $\begin{array}{l}\text { Median nerve has one additional contribution } \\
\text { from the lateral cord }\end{array}$ \\
\hline 6 & M & Typical & $\begin{array}{l}\text { Median nerve has one additional contribution } \\
\text { from the lateral cord and axillary nerve gives } \\
\text { rise to thoracodorsal and lower subscapular } \\
\text { nerve }\end{array}$ \\
\hline 11 & $\mathrm{~F}$ & Typical & Typical \\
\hline 12 & M & Typical & Typical \\
\hline 13 & $\mathrm{~F}$ & $\begin{array}{l}\text { Median nerve has one additional contribution from } \\
\text { the lateral cord }\end{array}$ & Typical \\
\hline 14 & M & Typical & Typical \\
\hline 15 & M & $\begin{array}{l}\text { Median nerve has one additional contribution from } \\
\text { the lateral cord }\end{array}$ & $\begin{array}{l}\text { Median nerve has two additional contribution } \\
\text { from the lateral cord }\end{array}$ \\
\hline 16 & M & Typical & $\begin{array}{l}\text { Median nerve has one additional contribution } \\
\text { from the lateral cord }\end{array}$ \\
\hline 17 & M & Typical & $\begin{array}{l}\text { Musculocutaneous nerve arises from the } \\
\text { anterior division of the upper trunk and the } \\
\text { axillary nerve arises from the posterior division } \\
\text { of the upper trunk only }\end{array}$ \\
\hline
\end{tabular}

From the 28 sides which were found without variation, 5 were from female cadavers and the rest from male cadavers. From the 10 cadavers with median nerve 3 were from female cadavers and the rest from male cadavers, the axillary and musculocutaneous nerve variations were found from male cadavers.

In 28 sides which were found without variation the musculocutaneous nerve arises from the lateral cord, median nerve formed by fusion of medial and lateral roots from medial and lateral cords respectively, ulnar nerve arises from the medial cord, axillary and radial nerves arise from the posterior cord (Figure 1).

From 10 sides of the cadavers with median nerve variation, 9 sides were having one additional root from the lateral cord or the median nerve was formed by three roots (Figure 2) and one cadaver had 2 additional roots from the lateral cord or it was formed by four roots (Figure 3 ). On the right side of a male cadaver, the 
musculocutaneous nerve arises from the median nerve. (Figure 4)

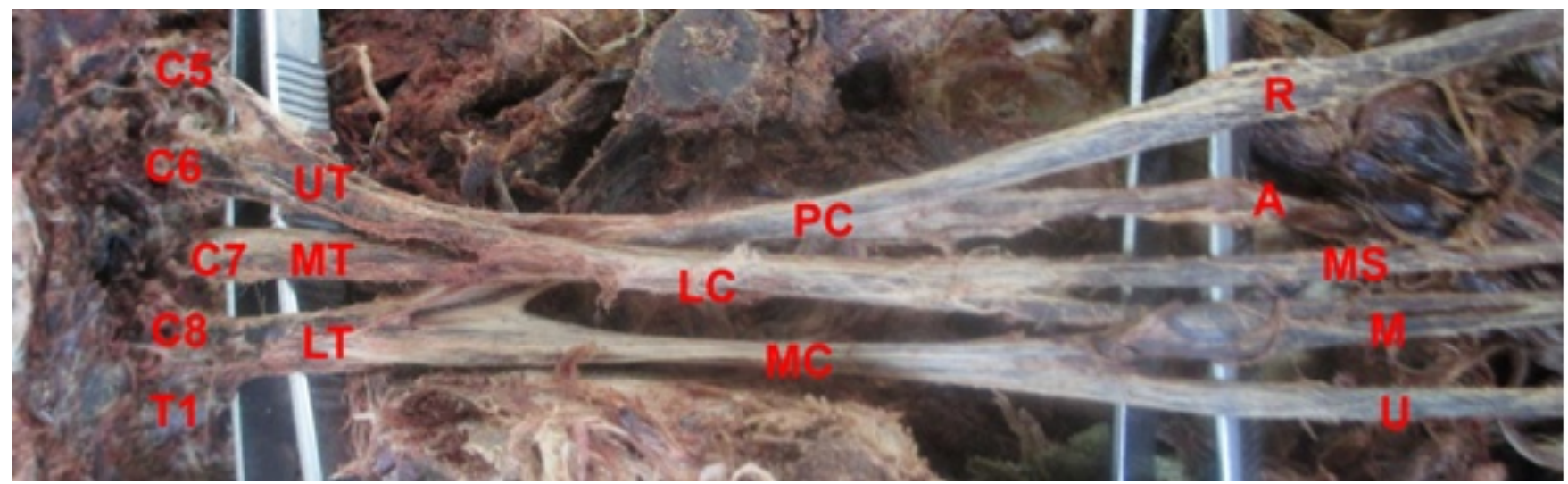

Figure1: A picture taken from left side Ethiopian cadaver illustrating the normal formation and terminal branches of brachial plexus. $\mathrm{C} 5=$ fifth Cervical spinal nerve, $\mathrm{C} 6=$ sixth Cervical spinal nerve, $\mathrm{C} 7=$ seventh Cervical spinal nerve, $\mathrm{C} 8=$ eighth Cervical spinal nerve , $\mathrm{T} 1=$ first Thoracic spinal nerve, $\mathrm{UT}=$ upper trunk, $\mathrm{MT}=$ middle trunk, $\mathrm{LT}=$ lower trunk, $\mathrm{LC}=$ lateral cord, $\mathrm{MC}=$ medial cord, $\mathrm{PC}=$ posterior cord, $\mathrm{A}=$ axillary nerve, $\mathrm{R}=$ radial nerve, $\mathrm{M}=$ median nerve, $\mathrm{MS}=$ musculocutaneous nerve, $\mathrm{U}=$ ulnar nerve

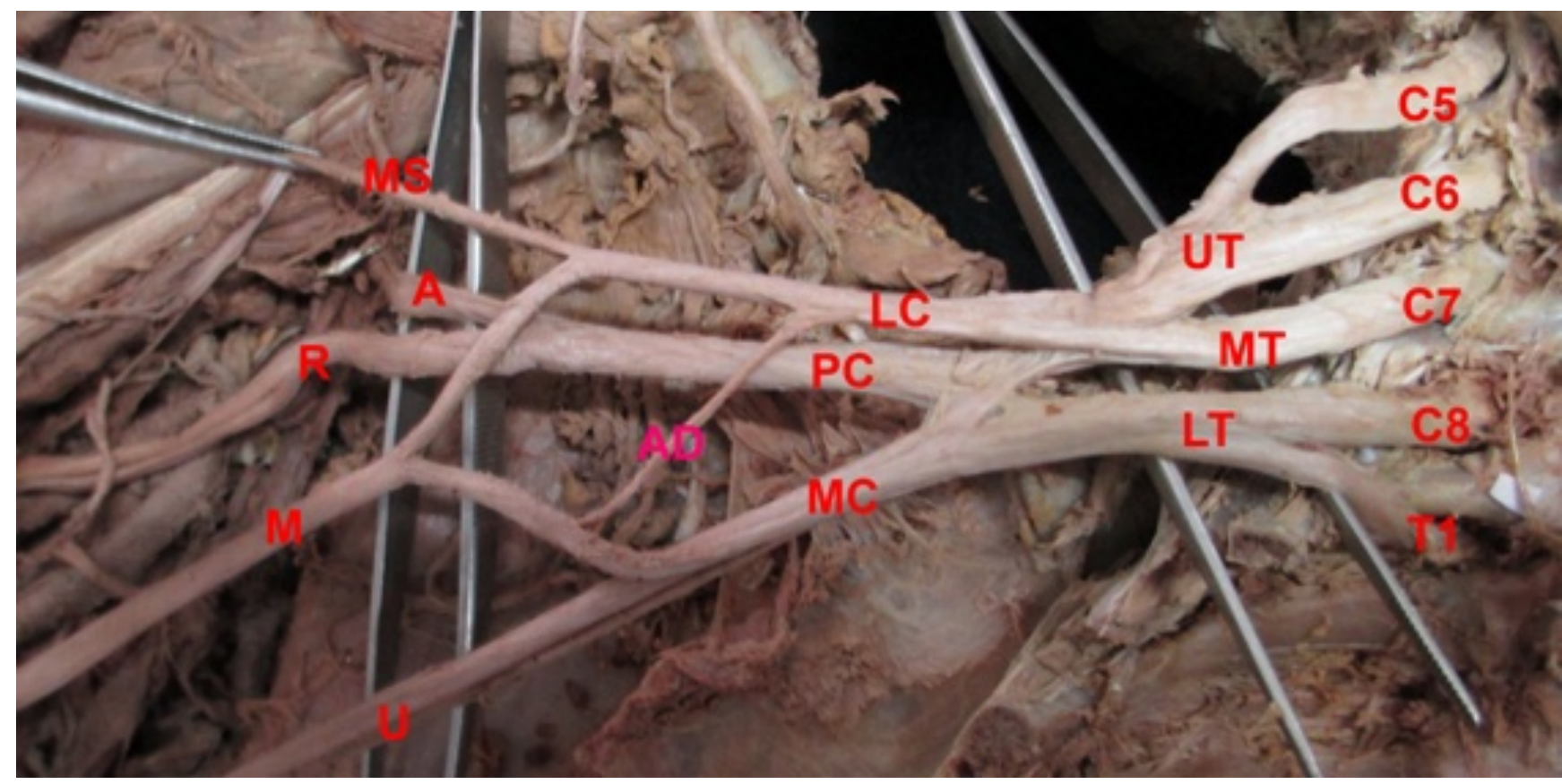

Figure 2: A picture taken from cadaver illustrating the median nerve formed by three roots, 2012 . $C 5=$ fifth Cervical spinal nerve, $\mathrm{C} 6=$ sixth Cervical spinal nerve, $\mathrm{C} 7=$ seventh Cervical spinal nerve, $\mathrm{C} 8=$ eighth Cervical spinal nerve, $\mathrm{T} 1=$ first Thoracic spinal nerve, UT=upper trunk, MT=middle trunk, $\mathrm{LT}=$ =lower trunk, $\mathrm{LC}=$ lateral cord, $\mathrm{MC}=$ medial cord, $\mathrm{PC}=$ posterior cord, $A=$ axillary nerve, $R=$ radial nerve, $M=$ median nerve, $M S=$ musculocutaneous nerve, $U=$ ulnar nerve, $A D=$ additional root 


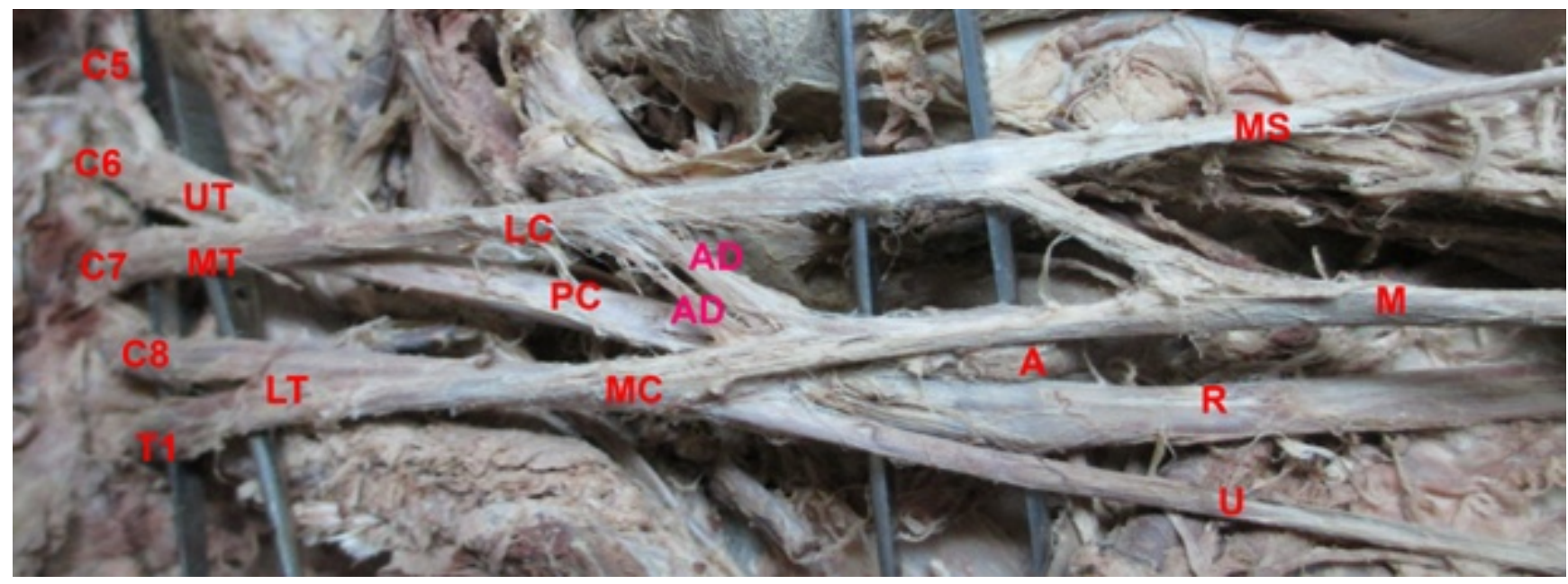

Figure 3: A picture taken from cadaver illustrating the median nerve formed by four roots, 2012. C5= Fifth Cervical spinal nerve, C6=Sixth Cervical spinal nerve, C7=Seventh Cervical spinal nerve , C8=Eighth Cervical spinal nerve, T1=FirstThoracic spinal nerve, UT=Upper Trunk, MT=Middle Trunk, LT=Lower Trunk, LC=Lateral Cord, MC=Medial Cord, PC=Posterior Cord, A=Axillary nerve, $\mathrm{R}=$ Radial nerve, $\mathrm{M}=$ Median nerve, $M S=$ Musculocutaneous nerve, $\mathrm{U}=$ Ulnar nerve, $A D=$ Additional root.

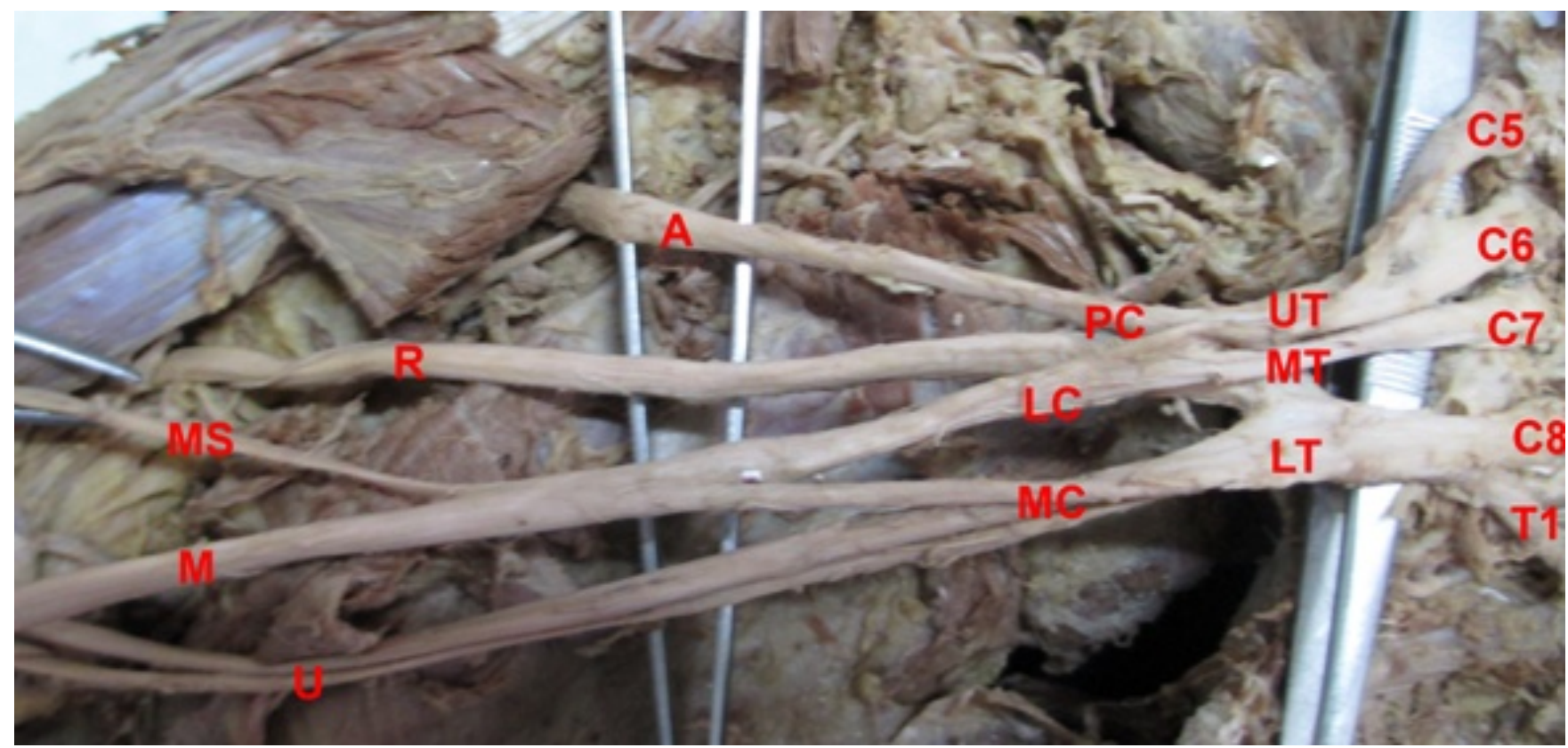

Figure 4: A picture taken from cadaver illustrating the musculocutaneous nerve arising from the median nerve, $2012 . \mathrm{C5}=$ fifth Cervical spinal nerve, $\mathrm{C} 6=$ sixth Cervical spinal nerve, $\mathrm{C7}=$ seventh Cervical spinal nerve , C8=eighth Cervical spinal nerve, $\mathrm{T} 1=$ first Thoracic spinal nerve, UT=upper trunk, MT=middle trunk, LT=lower trunk, $\mathrm{LC}=$ lateral cord, $\mathrm{MC}=$ medial cord, $\mathrm{PC}=\mathrm{posterior}$ cord, $A=$ axillary nerve, $\mathrm{R}=$ radial nerve, $\mathrm{M}=$ median nerve, $\mathrm{MS}=$ musculocutaneous nerve, $\mathrm{U}=$ ulnar nerve

On the left side of a male cadaver the musculocutaneous nerve arises from the anterior division of the upper trunk and the axillary nerve arises only from the posterior division of the Als www.anatomyafrica.org upper trunk (Figure 5). In another male cadaver on the left side the axillary nerve gives rise to thoracodorsal and lower subscapular nerve. (Figure 6) 


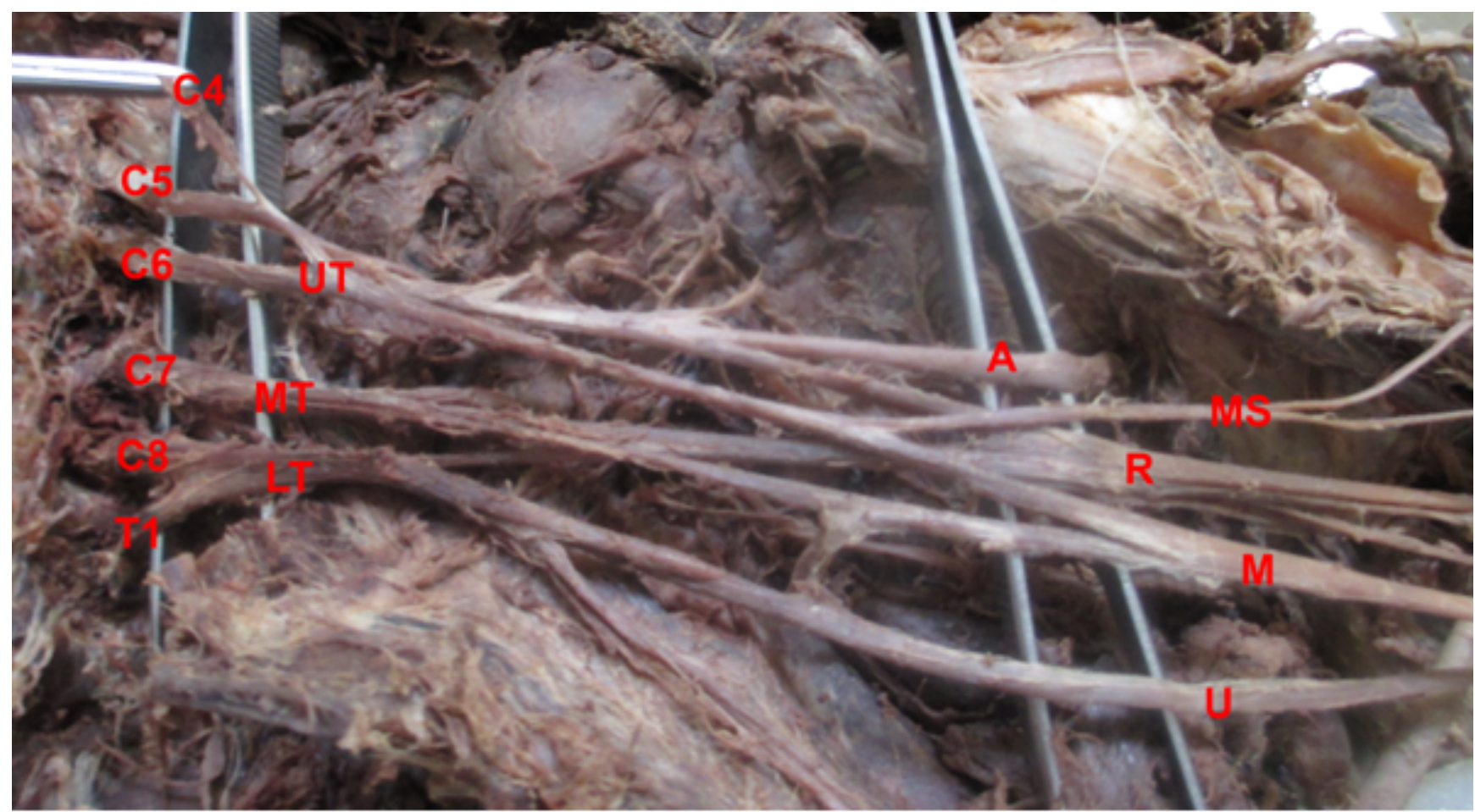

Figure 5: A picture taken from left side of one of the cadavers illustrating lack of cord formation, 2012. C4= fourth Cervical spinal nerve, $\mathrm{C} 5=$ fifth Cervical spinal nerve, $\mathrm{C} 6=$ sixth Cervical spinal nerve, $\mathrm{C} 7=$ seventh Cervical spinal nerve, $\mathrm{C} 8=$ eighth Cervical spinal nerve, $\mathrm{T} 1=$ first Thoracic spinal nerve, $\mathrm{UT}=$ upper trunk, $\mathrm{MT}=$ middle trunk, $\mathrm{LT}=$ lower trunk, $\mathrm{A}=$ axillary nerve, $\mathrm{R}=$ radial nerve, $\mathrm{M}=$ median nerve, $\mathrm{MS}=$ Musculocutaneous nerve, $\mathrm{U}=$ ulnar nerve

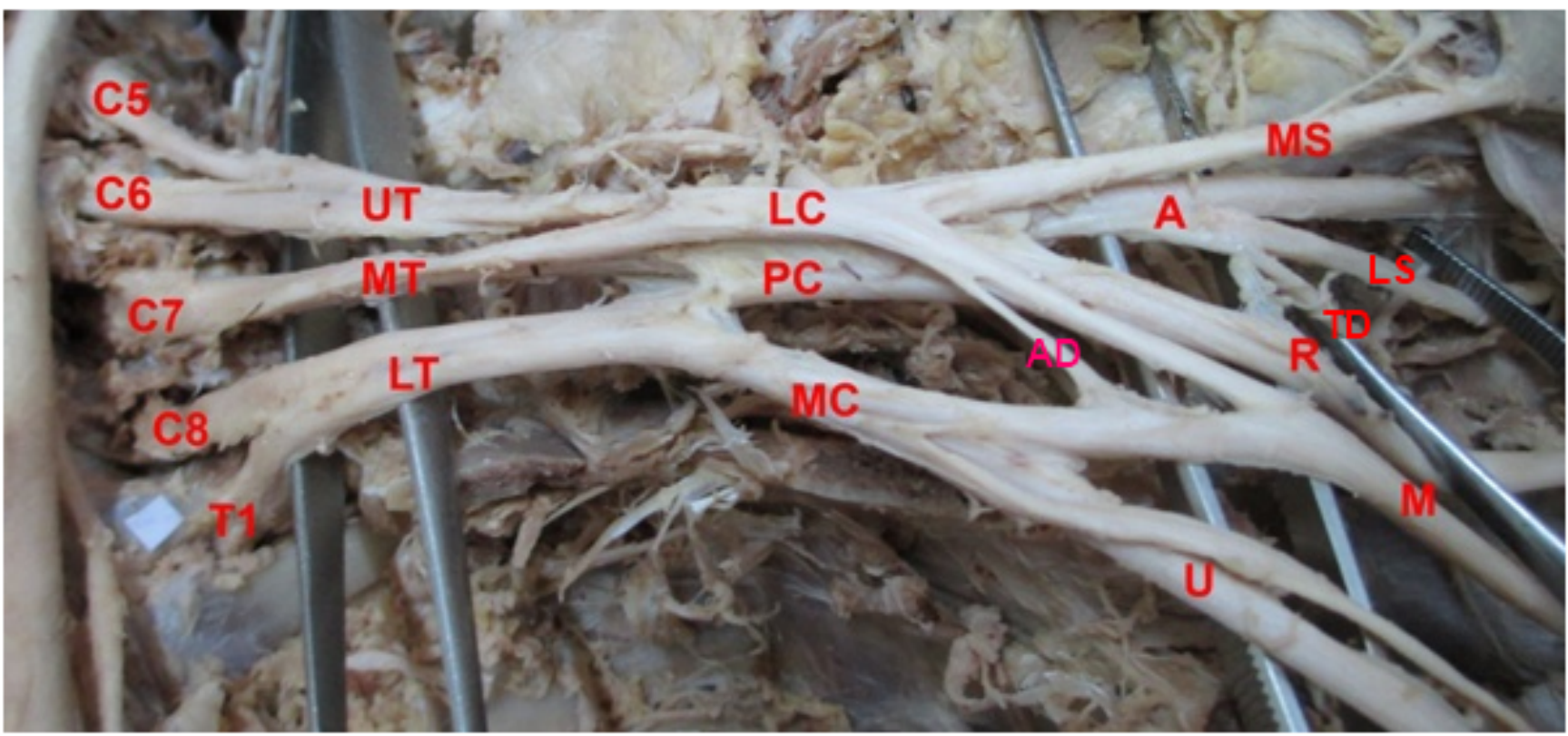

Figure 6: A picture taken from left side of Ethiopian cadaver illustrating Variation in the origin of thoracodorsal and lower subscapular nerve, 2012. C5= Fifth Cervical spinal nerve, C6=Sixth Cervical spinal nerve, C7=Seventh Cervical spinal nerve, 
C8=Eighth Cervical spinal nerve, T1=First Thoracic spinal nerve, UT=Upper Trunk, MT=Middle Trunk, LT=Lower Trunk, LC=Lateral Cord, MC=Medial Cord, PC=Posterior Cord, A=Axillary nerve, R=Radial nerve, M=Median nerve, $M S=$ Musculocutaneous nerve, $U=$ Ulnar nerve, $T D=$ Thoracodorsal nerve, $L S=$ Lower subscapular nerve, $A D=A d d i t i o n a l$ root

\section{DISCUSSION}

\section{Terminal branches of brachial plexus}

From the 20 cadavers or 40 sides studied, 28 sides were found normal without variation. 10 sides were found with median nerve variation. 2 sides were found with musculocutaneous nerve variation and 2 sides were found with axillary nerve variation.

From 10 sides of the cadavers with median nerve variation, 9 sides were having one additional root from the lateral cord or the median nerve was formed by three roots and one cadaver has 2 additional roots from the lateral cord or it's formed by four roots. But in a study conducted in Turkey using 65 cadavers or 130 plexuses, showed that a variation in the formation of the median nerve in four plexuses in which the median nerve was formed by fusion of three branches; one radix coming from the lateral cord; one intermediate radix directly from the middle trunk; and the normal medial radix from the medial cord. In 14 plexuses, there was a connection between the medial radix of the median nerve and the ventral division of the middle trunk. Two of the plexuses had a branch which arose from the posterior division of the middle trunk and connected to the medial cord (Uzun and Bilgic, 1999).

In this study in 9 sides the median nerve was formed by three roots and also in one case the musculocutaneous nerve arises from the median nerve. These finding was similar with the research done in India with 20 cadavers which showed that, in 1 case median nerve was formed by three roots and in another 1 case musculocutaneous nerve arises from median nerve (Porwal and DS, 2012, Maheria et al., 2013). Similarly, a research done in Nigeria with 90 cadavers showed that, the median and musculocutaneous nerves arise by a common

Als www.anatomyafrica.org stem from the lateral cord in 15 cadavers and the median nerve arise by multiple roots from the lateral and with just a tiny contribution from the medial cord (Adebisi and Singh, 2002).

In this study, in one side of a cadaver the radial nerve was formed by the union of posterior divisions of all the trunks but a research done in Turkey with Forty-eight upper limbs showed that, the radial nerve arose only from the union of posterior divisions of the inferior and middle trunks and connections between the musculocutaneous and median nerves were found in five arms (Pinar, 2001).

In this study, all the terminal branches were present in all the cases but a study done in India with 25 upper limbs bilaterally showed that variation in 3 limbs. In 1st limb musculocutaneous nerve was absent and the lateral cord was supplying the brachialis, coracobrachialis and biceps brachii muscles. In 2nd limb musculocutaneous nerve was coming from median nerve and in the 3rd case a communicating branch was coming from median nerve to musculocutaneous nerve in the middle of the arm (Chaudhary et al., 2011).

Out of the 40 posterior cords examined, two of them showed variation: one with the lower subscapular and thoracodorsal nerves arising from axillary nerve instead of directly from the posterior cord and the other one with lack of cord formation in which the axillary nerve arises from the posterior division of the upper trunk only and the radial nerve formed by the union of all the posterior divisions. But, a study conducted in Kenya with 68 cadavers showed that, only 8 posterior cords showed the classical branching pattern; forty three lower subscapular, 8 thoracodorsal and 8 upper subscapular nerves came from the axillary nerve instead of directly 
from posterior cord (Muthoka et al., 2011). Similarly another research done in India with 30 cadavers (60 upper limbs) showed that, normal branching pattern of the posterior cord in 52 limbs but the remaining 8 limbs showed variations in upper subscapular nerve, thoracodorsal nerve and axillary nerve. The radial nerve had a normal origin in all of the limbs (Chaudhary et al., 2011).

During this study, it was not possible to get large number of specimens or cadavers and most of the cadavers which have been used in this study were dissected bodies for teaching purpose so some of the structures needed were destroyed; these might be considered as the limitation of the research.

In conclusion, variations in the median nerve is more common than variations in other terminal branches. In order to improve and have reliability on the anatomical foundation further researches should be done in the terminal branches of brachial plexus. The detailed anatomical information provided in this report can be a base line for effective clinical practice for surgeons, anesthesiologists, radiologists and anatomists.

\section{REFERENCES}

1. Adebisi S, Singh S. 2002. Anomalous patterns of formation and distribution of the brachial plexus in Nigerians and the implication for brachial plexus block. Nigerian Journal of Surgical Research, 4, 103-106.

2. Chaudhary P, Singla R, Kalsey G, Arora K. 2011. Branching Pattern of the Posterior Cord of the Brachial Plexus: A Cadaveric Study. Journal of Clinical and Diagnostic Research, 5, 787-790.

3. Cunningham, D. J. 1903. Manual of practical anatomy, JB Lippincott Company.

4. Drake, R., VOGL, A. W. \& Mitchell, A. W. 2014. Gray's anatomy for students, Elsevier Health Sciences.

5. Harry, W. G., Bennett, J. D. \& Guha, S. C. 1997. Scalene muscles and the brachial plexus: anatomical variations and their clinical significance. Clin Anat, 10, 250-2.

6. Johnson, E. O., Vekris, M., Demesticha, T. \& Soucacos, P. N. 2010. Neuroanatomy of the brachial plexus: normal and variant anatomy of its formation. Surg Radiol Anat, 32, 291-7.

7. Loukas, M., Tubbs, R. S. \& Stewart, D. 2008. An abnormal variation of the brachial plexus with potential clinical significance. West Indian Med J, 57, 403-5.

8. Maheria, P. B., Chinna, N. G., Khubchandani, P. R., Upadhyay, A., Menezes, V. R., ChaudharY, M. L. \& Parchwani, D. 2013. A study of anatomical variations of the musculocutaneous nerve. Int J Res Med, 2, 1-4.

9. Moore, K. L. \& Dalley, A. F. 1992. The upper limb. Clinically oriented anatomy. Williams \& Wilkins, Baltimore.

10. Muthoka, J. M., Sinkeet, S. R., Shahbal, S. H., Matakwa, L. C. \& Ogeng'o, J. A. 2011. Variations in branching of the posterior cord of brachial plexus in a Kenyan population. Journal of brachial plexus and peripheral nerve injury, 6,1 .

11. Pellerin, M., Kimball, Z., Tubbs, R. S., Nguyen, S., Matusz, P., Cohen-GadoL, A. A. \& Loukas, M. 2010. The prefixed and postfixed brachial plexus: a review with surgical implications. Surg Radiol Anat, 32, 251-60.

12. Pinar, Y. A. 2001. A cadaveric study of the anatomic variations of the brachial plexus nerves in the axillar region and arm.

13. Porwal, S. \& DS, J. 2012. Variations in the infraclavicular part of brachial plexus-a dissection study. Anatomica Karnataka-an International Journal, 6, 62-65. 
14. Standring, S., Ellis, H., Healy, J., Johnson, D., Williams, A., Collins, P. \& Wigley, C. 2005. Gray's anatomy: the anatomical basis of clinical practice. American Journal of Neuroradiology, 26, 2703.

15. Uzun, A. \& Bilgic, S. 1999. Some variations in the formation of the brachial plexus in infants. Turkish Journal of Medical Sciences, 29, 573-578. 